\begin{tabular}{|c|c|}
\hline Title & $\begin{array}{l}\text { Phase II Study of Irinotecan plus S-1 Combination for Previously Untreated A dvanced Non-Small Cell Lung Cancer: } \\
\text { Hokkaido Lung Cancer Clinical Study Group Trial (HOT) } 0601\end{array}$ \\
\hline Author(s) & $\begin{array}{l}\text { A kie, Kenji; Oizumi, Satoshi; Ogura, Shigeaki; Shinagawa, Naofumi; Kikuchi, Eiki; Fukumoto, Shinichi; Harada, } \\
\text { Masao; Kinoshita, Ichiro; Kojima, Tetsuy a; Harada, Toshiy uki; Fuji ita, Y uka; O hsaki, Y oshinobu; Dosaka A kita, } \\
\text { Hirotoshi; I Isobe, Hiroshi; Nishimura, Masaharu }\end{array}$ \\
\hline Citation & $\begin{array}{l}\text { Oncology, 81(2), } 8490 \\
\text { https://doi.org/10.1159/000331681 }\end{array}$ \\
\hline Issue Date & $2011-10$ \\
\hline Doc URL & http://hdl .handle.net/2115/47435 \\
\hline Rights & (c) 2011 S. Karger A G, Basel \\
\hline Type & article (author version) \\
\hline File Information & Onc81-2_84-90.pdf \\
\hline
\end{tabular}

Instructions for use 


\section{Phase II study of irinotecan plus S-1 combination for previously untreated advanced non-small cell lung cancer: Hokkaido Lung Cancer Clinical Study Group Trial (HOT) 0601}

$K_{\text {Kenji Akie }}{ }^{1}$, M.D., Satoshi Oizumi ${ }^{2}$, M.D., Ph.D., Shigeaki Ogura ${ }^{1}$, M.D., Ph.D., Naofumi Shinagawa², M.D., Ph.D., Eiki Kikuchi², M.D., Ph.D., Shinichi Fukumoto $^{3}$, M.D., Ph.D., Masao Harada ${ }^{3}$, M.D., Ph.D., Ichiro Kinoshita ${ }^{4}$, M.D., Ph.D., Tetsuya Kojima ${ }^{5}$, M.D., Ph.D., Toshiyuki Harada ${ }^{6}$, M.D., Ph.D., Yuka Fujita $^{7}$, M.D., Ph.D., Yoshinobu Ohsaki ${ }^{8}$, M.D., Ph.D., Hirotoshi Dosaka-Akita ${ }^{4}$, M.D., Ph.D., Hiroshi Isobe ${ }^{5}$, M.D., Ph.D., and Masaharu Nishimura ${ }^{2}$, M.D., Ph.D.; Hokkaido Lung Cancer Clinical Study Group

${ }^{1}$ Department of Respiratory Medicine, Sapporo City General Hospital ${ }^{2}$ First Department of Medicine, Hokkaido University School of Medicine ${ }^{3}$ Department of Respiratory Medicine, National Hospital Organization Hokkaido Cancer Center ${ }^{4}$ Department of Medical Oncology, Hokkaido University Graduate School of Medicine 
${ }^{5}$ Department of Medical Oncology and Respiratory Medicine, KKR Sapporo Medical Center

${ }^{6}$ Center for Respiratory Disease, Hokkaido Social Insurance Hospital

${ }^{7}$ Department of Respiratory Medicine, National Hospital Organization Asahikawa

Medical Center

${ }^{8}$ Respiratory Center, Asahikawa Medical University

\section{Key Words}

irinotecan; S-1; chemotherapy; non-platinum; phase II, non-small cell lung cancer

\section{"Corresponding author}

Satoshi Oizumi

First Department of Medicine, Hokkaido University School of Medicine,

North 15, West 7, Kita-ku, Sapporo 060-8638, Japan.

Phone: +81-11-706-5911,

Fax: +81-11-706-7899,

E-mail: soizumi@med.hokudai.ac.jp 


\section{ABSTRACT}

Objective: Platinum-free regimens can represent an alternative for advanced non-small cell lung cancer (NSCLC) if similar efficacy is provided with better tolerability. This study evaluated the efficacy and safety of combined irinotecan and S-1 for chemotherapy-naïve advanced NSCLC.

Methods: Chemotherapy consisted of 4-week cycles of intravenous irinotecan (100 mg/m², days 1 and 15$)$ and oral $\mathrm{S}-1\left(80 \mathrm{mg} / \mathrm{m}^{2}\right.$, days $\left.1-14\right)$. The primary endpoint was response rate, while secondary endpoints were overall survival (OS), progression-free survival (PFS), and safety.

Results: A total of 112 cycles was administered to 40 patients (median, 3 cycles; range, 1-6 cycles). Twelve patients showed partial response (PR) and 17 patients exhibited stable disease (SD), representing a response rate of $30 \%$ and a disease control rate of $72.5 \%$. Median survival time and median PFS were 16.1 months and 4.8 months, respectively. Hematological toxicities of grade 3 or 4 were neutropenia (32.5\%) and anemia (5.0\%). The most common non-hematological toxicities of grade 3 or 4 included diarrhea (15.0\%) and anorexia $(17.5 \%)$. Patients homo- or heterozygous for UGTA1A*6 tended to show a higher incidence of grade 3 diarrhea $(p=0.055)$.

Conclusion: The combination of irinotecan and S-1 offers good efficacy and tolerability for previously untreated advanced NSCLC. 


\section{INTRODUCTION}

Platinum-based doublet chemotherapy was established in the 1990s, and it has become the standard first-line therapy for advanced non-small cell lung cancer (NSCLC) [1, 2]. Platinum compounds, particularly cisplatin, are associated with considerable toxicity that may lead to reluctance on the part of both physicians and patients to initiate chemotherapy. Platinum-free regimens can offer a useful substitute if similar efficacy can be provided with reduced toxicity.

Third-generation agents are, in general, better tolerated than their firstand second-generation predecessors, and have shown single-agent activity. The development of new anticancer drugs such as nucleoside analogs, vinca-alkaloids, taxanes, camptothecin-derivatives, and 5-fluorouracil derivatives provide alternatives to these platinum agents [3].

Among the new agents, irinotecan and S-1 have been developed in Japan. Irinotecan, a derivative of camptothecin, inhibits topoisomerase I and shows strong antitumor effects against NSCLC. Fukuoka et al. reported that irinotecan monotherapy showed a $23 \%$ response rate $(R R)$ with a median survival time (MST) of 42 weeks for previously untreated NSCLC [4]. In addition, irinotecan plus cisplatin exhibited a RR of $52 \%$, including 1 case of complete response (CR) with an MST of 44 weeks [5].

S-1 is a novel oral fluorouracil antitumor agent that consists of tegafur, 5-chloro-2,4-dihydroxypyridine (gimeracil, which inhibits dihydropyrimidine dehydrogenase) and potassium oxonate (oteracil potassium). In a phase II trial against metastatic NSCLC, S-1 showed a promising RR of $22 \%$ with an MST of 
10.5 months [6]. S-1 combined with cisplatin or carboplatin exhibited promising efficacy with favorable toxicity profiles [7-11]. In addition, the LETS (Lung Cancer Evaluation of TS-1) study recently demonstrated that S-1 with carboplatin was non-inferior in terms of overall survival (OS) compared with carboplatin and paclitaxel in patients with advanced NSCLC [12].

In preclinical models, optimal therapeutic synergy was observed with irinotecan plus S-1 or 5-fluorouracil combination $[13,14]$. The apoptosis rate of colon cancer cells increased after treatment with irinotecan plus 5-fluorouracil, corresponding to activation of Bax [13]. A potential mechanism of synergy between irinotecan plus S-1 was also suggested by the significant reduction in levels of thymidylate synthase [14].

Several studies of combination therapy with irinotecan plus S-1 have shown promising activity and safety, particularly for gastric or colorectal cancer $[15,16]$. These findings led us to investigate the possibility of irinotecan combined with S-1 as a first-line regimen for NSCLC. This prospective phase II study evaluated the efficacy and safety of irinotecan plus S-1 therapy. As a supplemental study, associations between UGT1A1 genotypes (*6 and ${ }^{*} 28$ ) and frequency of severe toxicity were also examined.

\section{PATIENTS AND METHODS}

\section{Patient Eligibility}

The ethics review boards at each participating institute approved this study, and each patient provided written informed consent prior to enrollment. Main eligibility criteria were: 1) histologically or cytologically confirmed NSCLC; 
2) stage III disease without indication for curative irradiation, stage IV disease, or postoperative recurrence; 3) no prior chemotherapy; 4) measurable or assessable disease; 5) Eastern Cooperative Oncology Group (ECOG) performance status (PS) 0-2; 6) age between 20 and 75 years with white blood cell (WBC) count $\geq 3,000 / \mathrm{mm}^{3}$, hemoglobin $\geq 9.5 \mathrm{~g} / \mathrm{dl}$, platelet count $\geq 100,000 / \mathrm{mm}^{3}$, total bilirubin $\leq 1.5 \mathrm{mg} / \mathrm{dl}$, aspartate aminotransferase and alanine aminotransferase less than twice the upper limit of normal, creatinine $\leq 1.5 \mathrm{mg} / \mathrm{dl}, \mathrm{P}_{\mathrm{a}} \mathrm{O}_{2} \geq 65$ Torr or $\mathrm{SpO}_{2} \geq 92 \%$; and 7 ) anticipated survival $\geq 3$ months. Main exclusion criteria were: 1) serious concomitant systemic disorders including severe heart failure, uncontrollable angina, hypertension, diabetes mellitus, interstitial pneumonia, active infection, ulcer, or another primary malignancy; 2) symptomatic brain metastases; 3) history of severe hypersensitivity; and 4) pregnancy.

\section{Treatment Schedule}

All patients received irinotecan $\left(100 \mathrm{mg} / \mathrm{m}^{2}\right)$ on days 1 and 15 . S-1 (40 $\mathrm{mg}$ for patients with body surface area (BSA) $\leq 1.25 \mathrm{~m}^{2} ; 50 \mathrm{mg}$ for patients with BSA $>1.25 \mathrm{~m}^{2}$ but $\leq 1.5 \mathrm{~m}^{2}$; and $60 \mathrm{mg}$ for patients with $\mathrm{BSA} \geq 1.5 \mathrm{~m}^{2}$ ) was administered twice daily for 2 weeks (days 1-14) followed by a 2-week pause. The treatment cycle was repeated every 4 weeks, and all patients received at least 4 cycles unless disease progressed, unacceptable toxicity occurred, the patient refused further treatment, or the physician decided to discontinue treatment. Second-line chemotherapy or other subsequent treatments were initiated at the discretion of the physician according to the protocol. 
During the cycle, irinotecan was administered on day 15 when the patient met the following criteria: leukocyte count $\geq 2,000 / \mathrm{mm}^{3}$; neutrophil count $\geq 1,000 / \mathrm{mm}^{3}$; platelet count $\geq 50,000 / \mathrm{mm}^{3}$; total bilirubin $\leq 1.5 \mathrm{mg} / \mathrm{dl}$; no diarrhea or infection $\geq$ grade 2 ; and no non-hematological toxicities $\geq$ grade 3 . S-1 was stopped for: leukocyte count $<2,000 / \mathrm{mm}^{3}$; neutrophil count $<1,000 / \mathrm{mm}^{3}$; platelet count $<50,000 / \mathrm{mm}^{3}$; total bilirubin $\geq 1.5 \mathrm{mg} / \mathrm{dl}$; infection or diarrhea $\geq$ grade 2 ; or non-hematological toxicities $\geq$ grade 3 .

Subsequent cycles were delayed until recovery for: leukocyte count $<3,000 / \mathrm{mm}^{3}$; neutrophil count $<1,500 / \mathrm{mm}^{3}$; platelet count $<100,000 / \mathrm{mm}^{3}$; total bilirubin $\geq 1.5 \mathrm{mg} / \mathrm{dl}$; any infection or diarrhea; PS worsened to $\geq \mathrm{PS} 3$; or any non-hematological toxicities $\geq$ grade 3 .

Dose reductions of both agents were made in subsequent cycles for: grade 4 neutropenia lasting $\geq 4$ days; febrile neutropenia; thrombocytopenia $<20,000 / \mathrm{mm}^{3}$; or non-hematological toxic effects $\geq$ grade 3 except for anorexia, nausea, and vomiting. The dose of either S-1 or irinotecan alone was reduced for the next course when S-1 was stopped longer than 4 days or irinotecan had not been administered on day 15 in the previous cycle. When the patient experienced adverse events even after the first reduction, no second reduction was permitted and the protocol treatment was terminated.

\section{Treatment Assessment}

Physical examination, electrocardiography, determination of PS, laboratory tests, and chest radiography were performed at baseline and repeated at least every 2 weeks during treatment. Tumor responses were 
assessed using chest radiography, computed tomography (CT), or magnetic resonance imaging $(\mathrm{MRI})$ (when clinically indicated) before and during treatment and repeated at least every month until progression. Responses were classified as $C R$, partial response (PR), stable disease (SD), progressive disease (PD) or non-evaluable (NE) on the basis of Response Evaluation Criteria in Solid Tumors (RECIST) 1.0 [17]. Disease control rate (DCR) was defined as the sum of the objective response ( $C R$ or $\mathrm{PR})$ rate plus the rate of $\mathrm{SD}$. Progression was defined as progressive disease according to RECIST 1.0, clinical progression as judged by the investigator, or death from any cause without progression. Clinical response data were all confirmed by a central review.

Progression-free survival (PFS) was counted from the date of enrollment to the date on which progressive disease was first confirmed by the assessment of the investigator. OS was calculated from the date of enrollment to the date of death or confirmation of survival. For patients without any events, data were censored on the last date with non-event status. The National Cancer Institute Common Toxicity Criteria (NCl-CTC) version 3.0 were used to grade adverse events.

\section{Study Endpoints and Statistical Considerations}

The primary endpoint was overall response rate (ORR). Sample size was calculated as 36 in total to confirm an RR of $40 \%$ as a desirable target level and RR of $20 \%$ as uninteresting with an alpha error of 0.05 and a power of 0.8 . Allowing for a patient ineligibility rate of $10 \%$, we initially planned to enroll 40 patients. Secondary endpoints were PFS, OS, and toxicity profiles. Survival 
outcomes were estimated using the Kaplan-Meier method.

\section{UGT1A1 Analyses}

All UGT1A1 analyses were performed at Bio Medical Laboratories (Tokyo, Japan) using the Invader assay. Briefly, DNA was extracted from peripheral blood samples according to instructions from the manufacturer. The Invader assay detects UGT1A1 genotypes by use of cleavase enzyme and a fluorescence resonance energy transfer cassette. Probes were designed for detecting the genotypes associated with $U G T 1 A 1^{*} 6$ and ${ }^{*} 28$. The UGT1A1*6 target site is $211 \mathrm{G} / \mathrm{A}$ in exon 1 , and $U G T 1 A 1^{*} 28$ has 7 TA repeats within the TATA box, as previously reported $[18,19]$.

\section{RESULTS}

\section{Patient Characteristics}

Forty patients (28 men, 12 women) from 8 institutions were enrolled in this study from August 2006 to July 2008. Patient characteristics are outlined in Table 1. Median age at the time of entry to the study was 64 years (range, 42-75 years). ECOG PS was 0 in 23 patients (57.5\%), and 32 patients (80\%) had stage IV disease. In addition, 29 (72.5\%) patients had adenocarcinoma, and 8 (20\%) had squamous cell carcinoma.

\section{Response to Therapy and Survival}

The 40 patients received a total of 112 cycles (median, 3 cycles; range, $1-6$ cycles), with 19 patients ( $47.5 \%$ ) completing $\geq 4$ cycles. The dose of agents 
was reduced in 14 patients (35\%) because of toxicities, and protocol treatment was terminated in 21 patients (52.5\%) before completion of 4 cycles. Of the 21 patients, treatment was discontinued in 9 patients because of disease progression and in 12 patients who experienced unacceptable toxicity (Table 2). Mean relative dose intensities of $\mathrm{S}-1$ and irinotecan were $95 \%$ each. Subsequently, 38 patents were assessable for tumor responses. Twelve patients exhibited PR, and 17 patients exhibited SD, resulting in a RR of $30 \%(95 \%$ confidence interval $(\mathrm{Cl}), 16.6-46.5 \%)$ and a disease control rate of $72.5 \%$ $(95 \% \mathrm{Cl}, 56.1-85.4$; Table 3). The lower end of the $95 \% \mathrm{Cl}$ was thus lower than the threshold ORR of $20 \%$, and the primary endpoint was not met. Disease progressed in 9 cases. The final survival assessment was carried out in March 2010 (>1 year after the last patient enrollment). With a median follow-up time of 16.1 months, MST and median PFS for all enrolled patients were 16.1 months $(95 \% \mathrm{Cl}, 10.3-22.0$ months) and 4.8 months $(95 \% \mathrm{Cl}, 3.8-6.3$ months $)$, respectively (Figs. 1, 2). One-year survival rate was $60.0 \%(95 \% \mathrm{Cl}$, $43.3-75.1 \%)$.

We then conducted post-hoc analysis to evaluate differences in efficacy outcomes between histological types. ORRs were $34.5 \%(95 \% \mathrm{Cl}, 17.9-54.3)$ in adenocarcinoma $(\mathrm{n}=29)$ and $12.5 \%(95 \% \mathrm{Cl}, 0.3-52.7)$ in squamous cell carcinoma $(n=8)$. In addition, the adenocarcinoma group showed an MST of 17.2 months $(95 \% \mathrm{Cl}, 13.7-22.7$ months), whereas the squamous cell carcinoma group had an MST of 9.3 months $(95 \% \mathrm{Cl}$, could not be determined). The Kaplan-Meier plot of overall survival by histological type is shown in Figure 3 . 


\section{Toxicity profiles}

Severe adverse events were uncommon and were manageable in most cases. Overall, the most common hematological adverse events were leukopenia (60.0\%), neutropenia (55.0\%), anemia $(70.0 \%)$, and thrombocytopenia (20.0\%), while the most common non-hematological adverse events were diarrhea (62.5\%), nausea (50.0\%), and anorexia (62.5\%). Stomatitis was of grade 1 to grade 2 in severity (grade 1, 3 cases; grade 2, 1 case). Hematological toxicities of grade 3 or 4 included leukopenia $(10.0 \%)$, neutropenia (32.5\%) and anemia (5.0\%). The most common non-hematological toxicities of grade 3 or 4 included diarrhea (15.0\%), nausea (7.5\%), and anorexia (17.5\%) (Table 4). Grade 2 interstitial lung disease was reported in 1 patient, resolving after termination of the protocol treatment. Subsequently, no treatment-related deaths were encountered.

\section{Treatment after protocol discontinuation}

Although any treatment was permitted, the majority of enrolled patients received platinum-based regimen as a second-line treatment. Twenty-two patients $(55.0 \%)$ received carboplatin plus paclitaxel, and 3 patients $(7.5 \%)$ received carboplatin plus docetaxel. Four patients $(10.0 \%)$ showed sensitive EGFR mutation, and all four received second-line gefitinib monotherapy, resulting in SD response. 


\section{UGT1A1 Genotype Analysis and Associations with Toxicity}

The 40 patients included 1 patient homozygous and 8 patients heterozygous for $U G T 1 A 1^{*} 6$, compared to 7 patients heterozygous for UGT1A1*28. No patients showed both genotypes. Patients who were homo- or heterozygous for $U G T A 1 A^{\star} 6$ showed a trend toward high incidence of grade 3 diarrhea $(p=0.055)$. No relationship was identified between grade 3 or 4 neutropenia and $U G T 1 A 1^{*} 6(p=0.32)$. The patient harboring homozygous UGTA1A*6 showed grade 3 neutropenia and diarrhea. No association of UGT1A1*28 with severe toxicity was observed. The grade 2 interstitial lung disease developed in a patient heterozygous for UGT1A1*28.

\section{DISCUSSION}

There is an obvious need for equally active but better-tolerated regimens to optimize therapy for advanced NSCLC. This phase II trial employing irinotecan plus S-1 as a first-line therapy for chemotherapy-naïve NSCLC revealed a promising RR of $30 \%$ and an MST of 16.1 months, although the primary endpoint of ORR was not met. Furthermore, toxicity was manageable overall, with low frequencies of grade 3 or 4 hematological and non-hematological toxicities including neutropenia, diarrhea, nausea, and anorexia. Collectively, the present study demonstrated irinotecan plus S-1 as a promising and well-tolerated regimen for first-line treatment of advanced NSCLC.

Of note was the finding that utilizing combination therapy, RR and MST were significantly inefficacious against squamous cell carcinoma compared to 
adenocarcinoma. A previous study found no significant difference in PFS or RR with cisplatin plus S-1 by histological type [20]. Irinotecan plus S-1 has been developed for gastrointestinal malignancies. A limited number of squamous cell carcinomas were treated in this study. So whether irinotecan plus S-1 is effective against non-adenocarcinoma histologies should be further evaluated.

Several randomized phase II trials have compared cisplatin-based therapy with cisplatin-free therapy in the first-line treatment setting. Docetaxel/gemcitabine and vinorelbine/cisplatin combinations showed similar efficacy (RR, $30.0 \%$ vs. $39.2 \%$, respectively) and survival data (MST, 9.0 months vs. 9.7 months, respectively), while the cisplatin-free regimen showed less toxicity [21]. Gemcitabine plus vinorelbine was also compared with cisplatin plus vinorelbine or cisplatin plus gemcitabine [22]. No significant differences in the primary endpoint of quality of life were seen between the platinum and non-platinum arms, with comparable MSTs of 38 and 32 weeks, respectively. Subsequent meta-analysis showed that non-platinum third-generation-based combination regimens offer comparable efficacy with less toxic profiles when compared with platinum-based regimens [23]. Our findings likewise showed that the efficacy of combined irinotecan and S-1 is equivalent to that of the reported platinum doublet regimens, although limitations exist in comparing results between different studies.

Two clinical trials using the S-1 and irinotecan combination for untreated NSCLC have recently been reported from Japan. In a phase I trial, patients with advanced NSCLC received S-1 $\left(80 \mathrm{mg} / \mathrm{m}^{2}\right)$ on days $1-14$ and irinotecan (50-80 $\mathrm{mg} / \mathrm{m}^{2}$ ) on days 1,8 , and 15 of each 28 -day cycle. That study concluded by 
recommending $70 \mathrm{mg} / \mathrm{m}^{2}$ as the weekly dose of irinotecan [24]. In the WJTOG 3505 phase II study, patients were treated with irinotecan at $150 \mathrm{mg} / \mathrm{m}^{2}$ on day 1 and oral S-1 at $80 \mathrm{mg} / \mathrm{m}^{2}$ on days $1-14$ every 3 weeks. That study showed an ORR of $28.6 \%$. Median PFS was 4.9 months, whereas median OS was 15 months, with favorable toxicity profiles [25]. Other non-platinum regimens utilizing S-1 have also been reported, such as docetaxel plus S-1 or gemcitabine plus S-1 [26-29]. Efficacies were almost the same, although higher rates of myelosuppression with $\geq$ grade 3 neutropenia were observed, particularly in the docetaxel plus S-1 arm.

A phase II trial of irinotecan and S-1 for advanced gastric cancer using the same treatment schedule as in the present study revealed good efficacy (RR, $54.2 \%)$ and dose intensity [16], which encouraged us to apply that schedule in the present study for NSCLC. Dose intensity in our study was $95 \%$ for S-1 and $95 \%$ for irinotecan, in line with the findings of the WJTOG 3505 study. Recently, the FIRIS study reported that PFS with irinotecan plus S-1 (IRIS) was non-inferior to that with FOLFIRI (fluorouracil and folinic acid plus irinotecan) in a second-line treatment setting for metastatic colorectal cancer [30]. In that study, irinotecan was also administered on days 1 and 15 for the IRIS regimen. The best treatment schedule of irinotecan plus S-1 for lung cancer has yet to be determined, warranting further studies.

Determination of UGT1A1 genotypes might be clinically useful for predicting severe toxicity by irinotecan. The presence of the $U G T 1 A 1^{*} 6$ allele was associated with severe grade 4 neutropenia compared with patients showing the reference genotype [18]. Genotypes either hetero- or homozygous 
for $U G T 1 A 1^{*} 28$ represent a significant risk factor for severe toxicity from irinotecan [19]. In this study, no association between UGT1A1 genotypes and severe toxicity was observed. As the trial was powered for the primary endpoint, supplemental analyses were based on smaller numbers of patients and statistically meaningful analysis may thus have been precluded. Some prospective trials are underway to clarify whether reducing irinotecan dose is necessary for patients showing UGT1A1 genotypes.

Various limitations to this study need to be considered. First, the majority of patients in this study had adenocarcinoma (73\%). Patient selection could thus have contributed to survival outcomes. Second, EGFR mutation testing was performed for 17 patients, accounting for $42.5 \%$ of enrolled patients. We were therefore unable to assess the effects of EGFR mutation on overall survival. Finally, the study population was entirely Japanese, and the efficacy of this combination therapy thus may not be valid among non-Asian NSCLC patients.

In conclusion, the regimen of irinotecan and S-1 conferred similar survival benefits with good tolerability when compared with previously reported platinum-based regimens. This combination might represent an alternative to first-line chemotherapies for advanced NSCLC, and a more extensive clinical trial is warranted to verify the efficacy of this regimen. 


\section{REFERENCES}

1. Schiller JH, Harrington D, Belani CP, Langer C, Sandler A, Krook J, Zhu J, Johnson $\mathrm{DH}$. Comparison of four chemotherapy regimens for advanced non-small-cell lung cancer. N Engl J Med 2002;346: 92-98.

2. Ohe Y, Ohashi Y, Kubota K, Tamura T, Nakagawa K, Negoro S, Nishiwaki Y, Saijo N, Ariyoshi Y, Fukuoka M. Randomized phase III study of cisplatin plus irinotecan versus carboplatin plus paclitaxel, cisplatin plus gemcitabine, and cisplatin plus vinorelbine for advanced non-small-cell lung cancer: Four-Arm Cooperative Study in Japan. Ann Oncol 2007;18: 317-323.

3. Grossi F, Aita M, Defferrari C, Rosetti F, Brianti A, Fasola G, Vinante O, Pronzato $\mathrm{P}$, Pappagallo G. Impact of third-generation drugs on the activity of first-line chemotherapy in advanced non-small cell lung cancer: a meta-analytical approach. The oncologist 2009;14: 497-510.

4. Fukuoka M, Niitani $H$, Suzuki A, Motomiya M, Hasegawa K, Nishiwaki $Y$, Kuriyama T, Ariyoshi Y, Negoro S, Masuda N, Sigenori N, Tetsuo T. A phase II study of CPT-11, a new derivative of camptothecin, for previously untreated non-small-cell lung cancer. J Clin Oncol 1992;10: 16-20.

5. Masuda N, Fukuoka M, Fujita A, Kurita Y, Tsuchiya S, Nagao K, Negoro S, Nishikawa $\mathrm{H}$, Katakami N, Nakagawa K, Niitani $\mathrm{H}$. A phase II trial of combination of CPT-11 and cisplatin for advanced non-small-cell lung cancer. CPT-11 Lung Cancer Study Group. Br J Cancer 1998;78: 251-256.

6. Kawahara M, Furuse K, Segawa Y, Yoshimori K, Matsui K, Kudoh S, Hasegawa K, Niitani H. Phase II study of S-1, a novel oral fluorouracil, in advanced non-small-cell lung cancer. Br J Cancer 2001;85: 939-943.

7. Ichinose Y, Yoshimori K, Sakai H, Nakai Y, Sugiura T, Kawahara M, Niitani H. S-1 plus cisplatin combination chemotherapy in patients with advanced non-small cell lung cancer: a multi-institutional phase II trial. Clin Cancer Res 2004;10: 7860-7864. 
8. Ozawa Y, Inui N, Naitoh T, Yasuda K, Nagayama M, Shirai T, Suganuma $\mathrm{H}$, Fujii M, Nakamura H, Suda T, Chida K. Phase II study of combination chemotherapy with S-1 and weekly cisplatin in patients with previously untreated advanced non-small cell lung cancer. Lung Cancer 2009;63: 68-71.

9. Tamura K, Okamoto I, Ozaki T, Kashii T, Takeda K, Kobayashi M, Matsui K, Shibata T, Kurata T, Nakagawa K, Fukuoka M. Phase I/II study of S-1 plus carboplatin in patients with advanced non-small cell lung cancer. Eur J Cancer 2009;45: 2132-2137.

10. Kubota K, Sakai H, Yamamoto N, Kunitoh H, Nakagawa K, Takeda K, Ichinose Y, Saijo N, Ariyoshi Y, Fukuoka M. A multi-institution phase I/II trial of triweekly regimen with S-1 plus cisplatin in patients with advanced non-small cell lung cancer. J Thorac Oncol 2010;5: 702-706.

11. Kaira K, Sunaga N, Yanagitani N, Imai H, Utsugi M, Iwasaki Y, Shimizu K, lijima $\mathrm{H}$, Tsurumaki $\mathrm{H}$, Tomizawa $\mathrm{Y}$, Hisada T, Ishizuka T, Saito R, Mori M. Phase 2 study of S-1 plus carboplatin in patients with advanced non-small cell lung cancer. Lung Cancer 2010;68: 253-257.

12. Okamoto I, Yoshioka H, Morita S, Ando M, Takeda K, Seto T, Yamamoto N, Saka H, Asami K, Hirashima T, Kudoh S, Satouchi M, Ikeda N, Iwamoto Y, Sawa T, Miyazaki M, Tamura K, Kurata T, Fukuoka M, Nakagawa K. Phase III trial comparing oral S-1 plus carboplatin with paclitaxel plus carboplatin in chemotherapy-naive patients with advanced non-small-cell lung cancer: results of a west Japan oncology group study. J Clin Oncol 2010;28: 5240-5246.

13. Azrak RG, Cao S, Slocum HK, Toth K, Durrani FA, Yin MB, Pendyala L, Zhang W, McLeod HL, Rustum YM. Therapeutic synergy between irinotecan and 5-fluorouracil against human tumor xenografts. Clin Cancer Res 2004;10: 1121-1129.

14. Takiuchi H, Kawabe S, Gotoh M, Katsu K. Thymidylate synthase gene 
expression in primary tumors predicts activity of s-1-based chemotherapy for advanced gastric cancer. Gastrointest Cancer Res 2007;1: 171-176.

15. Goto A, Yamada Y, Yasui H, Kato K, Hamaguchi T, Muro K, Shimada Y, Shirao K. Phase II study of combination therapy with S-1 and irinotecan in patients with advanced colorectal cancer. Ann Oncol 2006;17: 968-973.

16. Komatsu Y, Yuki S, Fuse N, Kato T, Miyagishima T, Kudo M, Kunieda Y, Tateyama M, Wakahama O, Meguro T, Sakata Y, Asaka M. Phase 1/2 clinical study of irinotecan and oral S-1 (IRIS) in patients with advanced gastric cancer. Adv Ther 2010;27: 483-492.

17. Therasse P, Arbuck SG, Eisenhauer EA, Wanders J, Kaplan RS, Rubinstein L, Verweij J, Van Glabbeke M, van Oosterom AT, Christian MC, Gwyther SG. New guidelines to evaluate the response to treatment in solid tumors. European Organization for Research and Treatment of Cancer, National Cancer Institute of the United States, National Cancer Institute of Canada. J Natl Cancer Inst 2000;92: 205-216.

18. Jada SR, Lim R, Wong Cl, Shu X, Lee SC, Zhou Q, Goh BC, Chowbay B. Role of UGT1A1*6, UGT1A1*28 and ABCG2 c.421C>A polymorphisms in irinotecan-induced neutropenia in Asian cancer patients. Cancer Sci 2007;98: 1461-1467.

19. Ando Y, Saka H, Ando M, Sawa T, Muro K, Ueoka H, Yokoyama A, Saitoh $S$, Shimokata K, Hasegawa $\mathrm{Y}$. Polymorphisms of UDP-glucuronosyltransferase gene and irinotecan toxicity: a pharmacogenetic analysis. Cancer Res 2000;60: 6921-6926.

20. Yamamoto N, Yamanaka T, Ichinose Y, Kubota K, Sakai H, Gemma A, Saijo N, Fukuoka M, Niitani H. Pooled analysis of S-1 trials in non-small cell lung cancer according to histological type. Anticancer research 2010;30: 2985-2990.

21. Georgoulias V, Ardavanis A, Tsiafaki X, Agelidou A, Mixalopoulou P, Anagnostopoulou O, Ziotopoulos P, Toubis M, Syrigos K, Samaras N, 
Polyzos A, Christou A, Kakolyris S, Kouroussis C, Androulakis N, Samonis G, Chatzidaki D. Vinorelbine plus cisplatin versus docetaxel plus gemcitabine in advanced non-small-cell lung cancer: a phase III randomized trial. J Clin Oncol 2005;23: 2937-2945.

22. Gridelli C, Gallo C, Shepherd FA, Illiano A, Piantedosi F, Robbiati SF, Manzione L, Barbera S, Frontini L, Veltri E, Findlay B, Cigolari S, Myers R, lanniello GP, Gebbia V, Gasparini G, Fava S, Hirsh V, Bezjak A, Seymour L, Perrone F. Gemcitabine plus vinorelbine compared with cisplatin plus vinorelbine or cisplatin plus gemcitabine for advanced non-small-cell lung cancer: a phase III trial of the Italian GEMVIN Investigators and the National Cancer Institute of Canada Clinical Trials Group. J Clin Oncol 2003;21: 3025-3034.

23. D'Addario G, Pintilie M, Leighl NB, Feld R, Cerny T, Shepherd FA. Platinum-based versus non-platinum-based chemotherapy in advanced non-small-cell lung cancer: a meta-analysis of the published literature. $J$ Clin Oncol 2005;23: 2926-2936.

24. Ishimoto O, Ishida T, Honda Y, Munakata M, Sugawara S. Phase I study of daily S-1 combined with weekly irinotecan in patients with advanced non-small cell lung cancer. Int J Clin Oncol 2009;14: 43-47.

25. Okamoto I, Nishimura T, Miyazaki M, Yoshioka H, Kubo A, Takeda K, Ebi N, Sugawara S, Katakami N, Fukuoka M, Nakagawa K. Phase II study of combination therapy with S-1 and irinotecan for advanced non-small cell lung cancer: west Japan thoracic oncology group 3505. Clin Cancer Res 2008;14: 5250-5254.

26. Atagi S, Kawahara M, Kusunoki $Y$, Takada M, Kawaguchi T, Okishio K, Kubo A, Uehira K, Yumine K, Tomizawa Y, Saito R, Fukai S, Komatsu H. Phase I/II study of docetaxel and S-1 in patients with previously treated non-small cell lung cancer. J Thorac Oncol 2008;3: 1012-1017.

27. Segawa Y, Kiura K, Hotta K, Takigawa N, Tabata M, Matsuo K, Yoshioka H, Hayashi H, Kawai H, Aoe K, Maeda T, Ueoka H, Tanimoto M. A 
randomized phase II study of a combination of docetaxel and S-1 versus docetaxel monotherapy in patients with non-small cell lung cancer previously treated with platinum-based chemotherapy: results of Okayama Lung Cancer Study Group (OLCSG) Trial 0503. J Thorac Oncol 2010;5: 1430-1434.

28. Satouchi M, Kotani $Y$, Katakami N, Shimada T, Urata $Y$, Yoshimura $S$, Funada $\mathrm{Y}$, Hata A, Ando M, Negoro S. Randomized phase II study of two different schedules of gemcitabine and oral S-1 in chemo-naive patients with advanced non-small cell lung cancer. J Thorac Oncol 2010;5: 696-701.

29. Takiguchi Y, Tada Y, Gemma A, Kudoh S, Hino M, Yoshimori K, Yoshimura A, Nagao K, Niitani H. Phase I//I study of docetaxel and S-1, an oral fluorinated pyrimidine, for untreated advanced non-small cell lung cancer. Lung Cancer 2010;68: 409-414.

30. Muro K, Boku N, Shimada Y, Tsuji A, Sameshima S, Baba H, Satoh T, Denda T, Ina K, Nishina T, Yamaguchi K, Takiuchi H, Esaki T, Tokunaga S, Kuwano H, Komatsu Y, Watanabe M, Hyodo I, Morita S, Sugihara K. Irinotecan plus S-1 (IRIS) versus fluorouracil and folinic acid plus irinotecan (FOLFIRI) as second-line chemotherapy for metastatic colorectal cancer: a randomised phase $2 / 3$ non-inferiority study (FIRIS study). Lancet Oncol 2010;11: 853-860. 


\section{FIGURE LEGENDS}

Figure 1. Overall survival, median 16.1 months $(95 \% \mathrm{Cl}, 10.3-22.0$ months)

Figure 2. Progression-free survival, median 4.8 months $(95 \% \mathrm{Cl}, 3.8-6.3$ months $)$

Figure 3. Overall survival by histological type, median 17.2 months $(95 \% \mathrm{Cl}$, 13.7-22.7 months) for adenocarcinoma and 9.3 months $(95 \% \mathrm{Cl}$, could not be determined) for squamous cell carcinoma 


\section{Figure 1. Overall Survival}

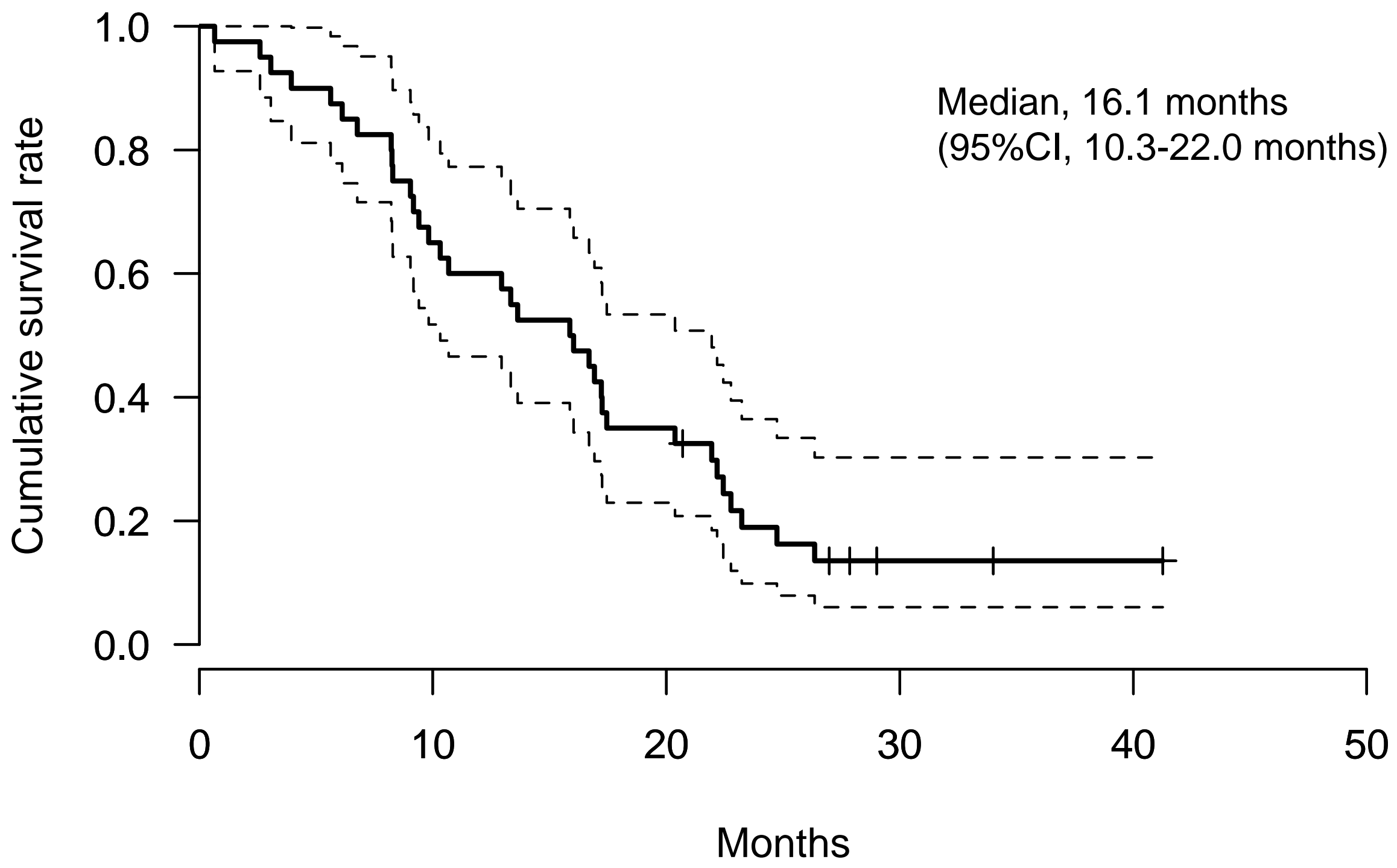




\section{Figure 2. Progression-free Survival}

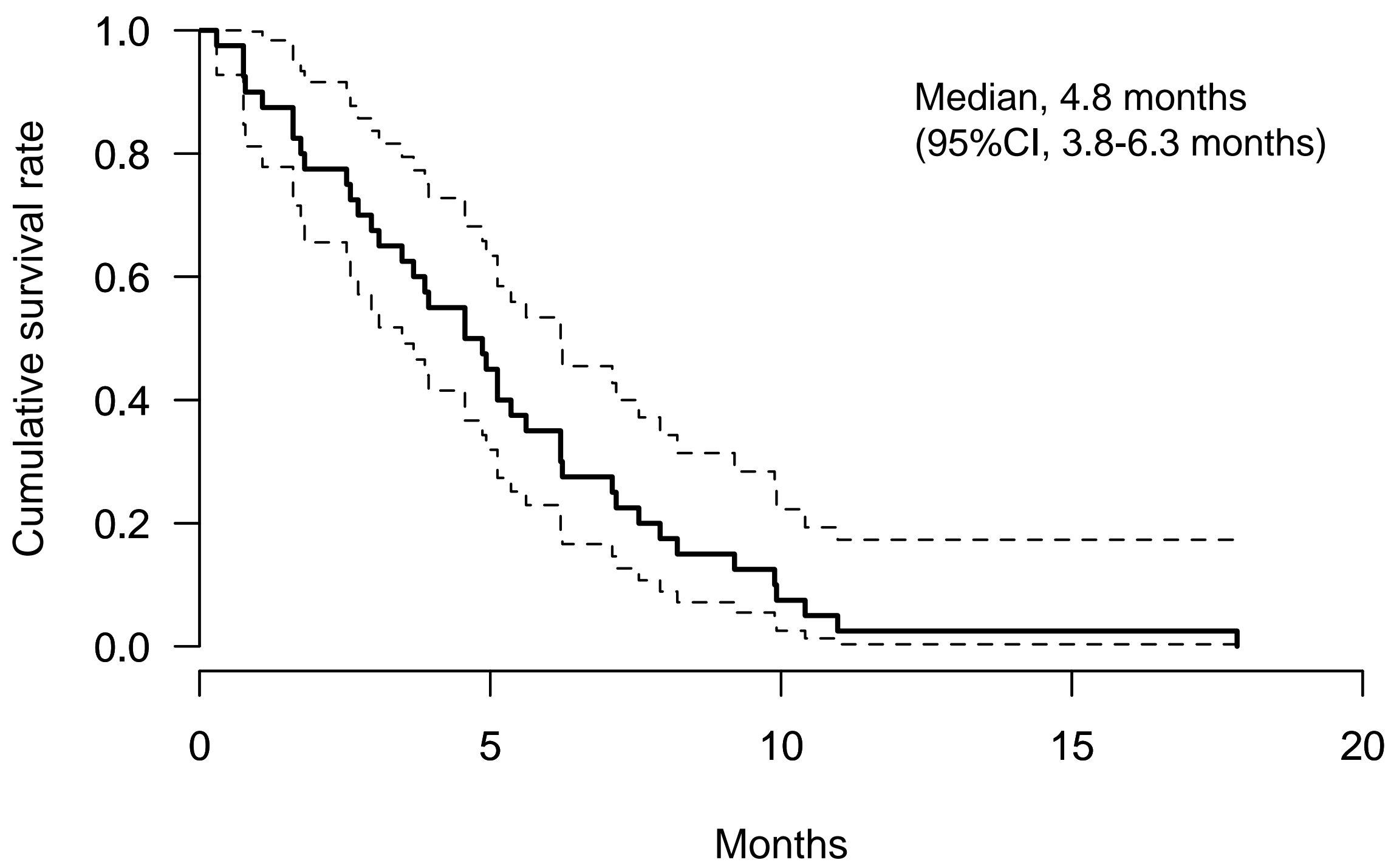




\section{Figure 3. Overall Survival by Histological Type}

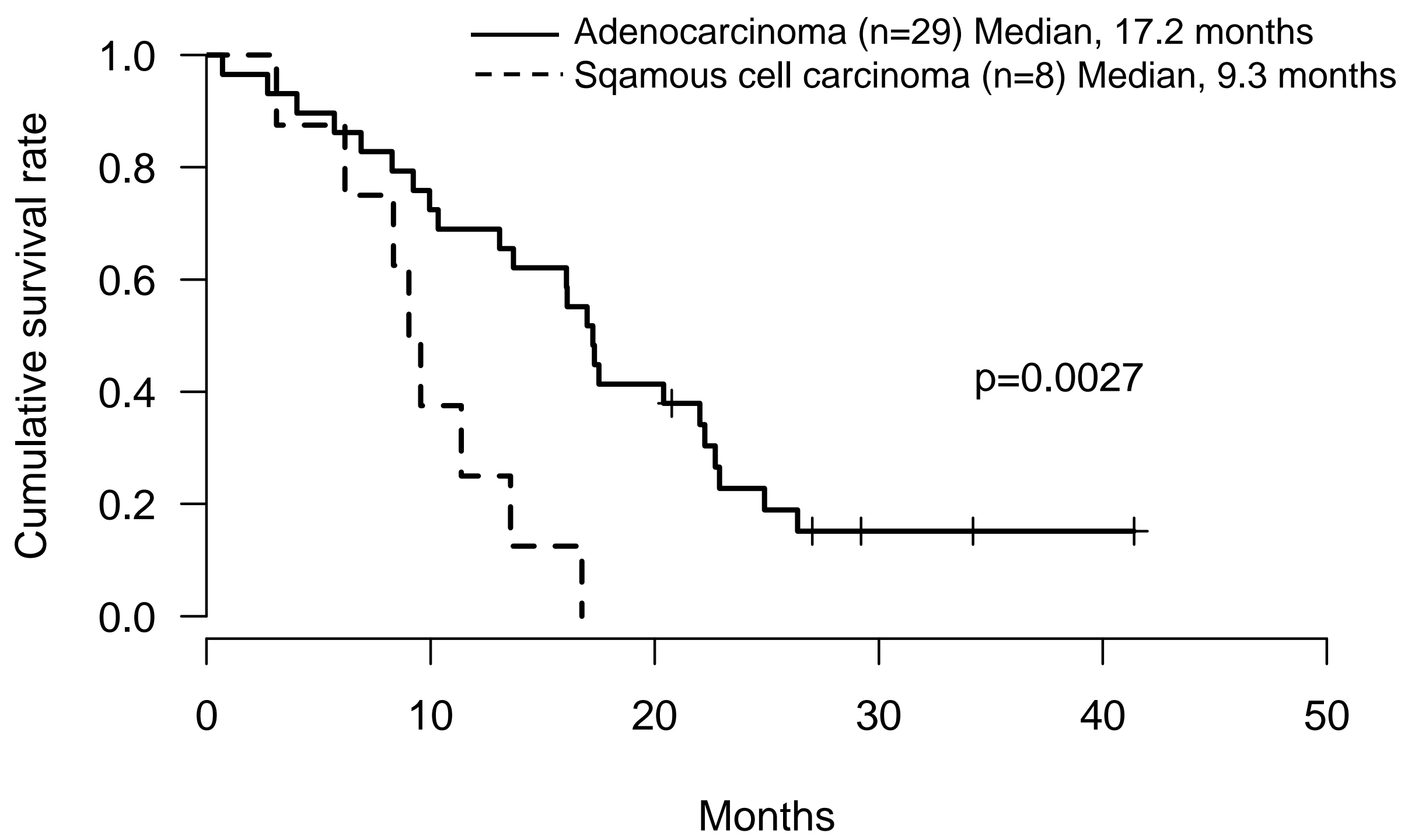


Table 1. Patient characteristics

\begin{tabular}{|c|c|c|}
\hline Characteristic & $\mathrm{n}$ & $(\%)$ \\
\hline \multicolumn{3}{|l|}{ Age (years) } \\
\hline Median & 64 & \\
\hline Range & $42-75$ & \\
\hline \multicolumn{3}{|l|}{ Sex } \\
\hline Male & 28 & 70.0 \\
\hline Female & 12 & 30.0 \\
\hline \multicolumn{3}{|l|}{ ECOG performance status } \\
\hline 0 & 23 & 57.5 \\
\hline 1 & 17 & 42.5 \\
\hline \multicolumn{3}{|l|}{ Disease stage } \\
\hline IIIB & 6 & 15.0 \\
\hline IV & 32 & 80.0 \\
\hline Recurrence after surgery & 2 & 5.0 \\
\hline \multicolumn{3}{|l|}{ Histology } \\
\hline Adenocarcinoma & 29 & 72.5 \\
\hline Squamous cell carcinoma & 8 & 20.0 \\
\hline Unclassified NSCLC & 3 & 7.5 \\
\hline
\end{tabular}

Abbreviations: ECOG, Eastern Cooperative Oncology Group; NSCLC, non-small-cell lung cancer. 
Table 2. Reason for discontinuation of protocol treatment

\begin{tabular}{lcccc}
\hline & Cycle 1 & Cycle 2 & Cycle 3 & Total \\
\hline Disease progression & 4 & 3 & 2 & 9 \\
Unacceptable toxicity & 4 & 6 & 2 & 12 \\
\hline
\end{tabular}


Table 3. Overall response

\begin{tabular}{lc}
\hline Response & $\mathrm{n}(\%)$ \\
Complete response & $0(0 \%)$ \\
Partial response & $12(30 \%)$ \\
Stable disease & $17(42.5 \%)$ \\
Progressive disease & $9(22.5 \%)$ \\
Not evaluable & $2(5.0 \%)$ \\
\hline Response rate: $30 \%(95 \% \mathrm{Cl}, 16.6-46.5 \%)$ \\
$\begin{array}{l}\text { Disease control } \\
56.1-85.4 \%)\end{array}$
\end{tabular}


Table 4. Toxicity for all cycles

\begin{tabular}{|c|c|c|c|c|c|}
\hline \multirow[t]{2}{*}{ Toxicity } & \multicolumn{4}{|c|}{ Grade } & \multirow[t]{2}{*}{ Grade $\geq 3(\%)$} \\
\hline & 1 & 2 & 3 & 4 & \\
\hline Leukopenia & 9 & 11 & 4 & 0 & 10.0 \\
\hline Neutropenia & 5 & 4 & 12 & 1 & 32.5 \\
\hline Anemia & 14 & 12 & 2 & 0 & 5.0 \\
\hline Thrombocytopenia & 7 & 1 & 0 & 0 & 0 \\
\hline Diarrhea & 12 & 7 & 6 & 0 & 15.0 \\
\hline Nausea & 10 & 7 & 3 & 0 & 7.5 \\
\hline Vomiting & 2 & 3 & 1 & 0 & 2.5 \\
\hline Anorexia & 13 & 5 & 7 & 0 & 17.5 \\
\hline
\end{tabular}

